\title{
Design of a Small Movable Lifting Machine Overall Structure
}

\author{
Yingchun Liu
}

Weifang University of Science \& Technology, Shandong, Shouguang, 262700, China.

\author{
Keywords: Lifting machine; Bearing; Pulling force; Welding
}

\begin{abstract}
The paper is mainly on the overall structural design of small movable lifting machine . First of all, it selects the main components, the need to include: H-K201 micro electric hoist, steel wire rope and bearing. Then it comes to the corresponding design calculation, including the requirements for welding, pulling force calculation, wire rope tension calculation, shaft and external dipole moment calculation. It also emphasizes the requirements of the crane. At the end, the paper summarizes the design process.
\end{abstract}

\section{Introduction}

The lifting machine is one of the large fixed machines, which is mainly used for lifting and conveying all kinds of heavy loads. The small elevator plays an important role in daily life. The power source of the host chooses the micro electric hoist, The three parts which are the motor, the reducer and the roller are connected by the coupling respectively. The motor is the power source, the reducer is the drive system and the roller is the execution and the control part, in which the reducer is the most important which uses quasi parallel torus worm. The worm bearing power is big, the dynamic pressure oil is stable, the noise is low and the balance temperature is low, which has both superior practical value and economic value.

\section{Selection of major components}

Selection of H-K201 miniature electric hoist. Electric hoist and electric hoist. Micro electric hoist is suitable for various occasions, which can enhance 1000 kilogram of subsequent goods. It is especially used in high-rise buildings when lifting heavy goods from the ground floor. It has the advantages of simple, dainty structure, convenient installation, little size. What's more, it uses one-way electricity as power source. Micro electric hoist has achieved the international standard in the production design and ensured the safety of the motor. The electric heat sink adopts cast iron structure, which improves the service life. Micro electric hoist can be utilized in the production and construction of factories, mines, agriculture, power, construction, dock, warehouse machinery installation, cargo lifting, vehicle handling and other operations. The rated voltage of the miniature electric hoist is $220 \mathrm{~V}$ which is suitable for the workshop of the hou sehold and the three-phase electricity. Due to the target surface tension, two adults are needed to pull up, which weight is more than 1000 kilograms. It shows that the selection of $\mathrm{H}-\mathrm{K} 201$ micro electric hoist fully meets the requirements.

Wire rope selection. Choosing appropriate wire rope can decrease the risk factors in use and the harm to people, machine, and can prevent premature damage. The choice of wire rope should not only considers the breaking force and twisting direction, rope, rope core structure, anti rotation property and lubricating property factors, but also takes into account the actual condition of heavy machinery. In order to improve the service life, wire rope should be as far as possible and the contact wire rope should not be chosen. It is not appropriate to choose the wire rope with high strength, and its strength should not exceed $2160 \mathrm{MPa}$. The operating conditions of the lifting molten or hot metal shall be the asbestos core and the high temperature wire rope. From the above analysis, the wire rope diameter should be 6 . 
Bearing selection. Considering the action of radial force, 6306 bearings should be chosen. The dynamic load size should be $40.8 \mathrm{KN}$ which is static load and the size should be $24 \mathrm{KN}$. Torque and shaft are calculated to meet the requirements. The speed limit in grease can reach $7000 \mathrm{rpm}$ to meet the requirements. The bearing with various of bearing seats which are directly in stalled on the shaft.

Lower shaft bearings does not only need to bear the radial force, but also need to bear vertical pressure, so the thrust bearing is chosen. The size of the load should be $10.8 \mathrm{KN}$ and the static load should be $14 \mathrm{KN}$. A xial computes torque to meet the requirements. The speed limit in grease can reach 3800 rotational speed in revolutions per minute. Due to the bearing selection, the bearing seal should, according to the common seal, use industrial wool to meet the requirements, which replaces comparison, reduces price and has very good function that effectively prevents debris in the bearing internal from influencing the service life of the bearing. So all parts adopt wool felt seals. Then it selects 6306 spherical roller bearing s. Thru st bearing is 51206.

\section{Design calculation part}

Welding require ments. Selection of welding parameters. Through the analysis of the welding, the measures are as follows:

Selection of welding material

Due to the cold crack of Q345, steel tends to be larger and low hydrogen welding material, while the welding joint shall be strong as the base material with the principle of the selected model: E5015 grade: J507 or types: E5016 grades:j506 welding a.

Groove form: the K type groove, angle of 45 or 60 degrees.

Welding method: manual welding.

Welding current: in order to avoid the large weld micro structure, the impact toughness is reduced, and the welding of small specification must be used.

The specific measures are: The small diameter welding electrode, bead, thin layer, the multi pass welding. 3 times the bead width is less than the electrode, welding layer thickness is not greater than $5 \mathrm{~mm}$. The diameter of the first layer of the third layer is 3.2 welding electrodes. Welding current is 100-130A; the diameter of the fourth layer of the sixth layer is $4.0 \mathrm{~b}$ ar welding of electrodes. Welding current is $120-180 \mathrm{~A}$.

Preheat temperature: before welding, preheating temperature is 100-150.

Tension calculation process. The technical parameters of the micro electric hoist for the micro electric hoist of the hoist

H-K technology data:

\begin{tabular}{|c|c|c|c|c|c|c|c|c|}
\hline TYPE & $\begin{array}{l}\text { Rated } \\
\text { Volt } \\
(\mathrm{V} \sim)\end{array}$ & $\begin{array}{l}\text { Input } \\
\text { Power } \\
\text { (w) }\end{array}$ & $\begin{array}{l}\text { Rated } \\
\text { Lift ing } \\
\text { Weight }( \\
\mathrm{kg})\end{array}$ & $\begin{array}{l}\text { Lifting } \\
\text { height( } \\
\text { m) }\end{array}$ & $\begin{array}{l}\text { Lifting } \\
\text { Speed } \\
(\mathrm{m} / \mathrm{min})\end{array}$ & $\begin{array}{l}\text { Packin } \\
\text { g } \\
\text { dim-en } \\
\text { sion (c } \\
\text { m) }\end{array}$ & $\begin{array}{l}\text { G.w. } \\
\text { /n.w. } \\
\text { (kg) }\end{array}$ & $\begin{array}{l}\text { Quan/ } \\
\text { ctn } \\
\text { (pcs) }\end{array}$ \\
\hline $\begin{array}{l}\mathrm{H}-\mathrm{K} 2 \\
01\end{array}$ & \multirow[t]{3}{*}{$\begin{array}{l}230 \sim \\
50 \mathrm{HZ}\end{array}$} & 1150 & 200 & 25 & 15 & $\begin{array}{l}53 \times 45 \\
\times 19 \\
\end{array}$ & $\begin{array}{l}41 / 3 \\
8\end{array}$ & 2 \\
\hline $\begin{array}{l}\mathrm{H}-\mathrm{K} 2 \\
02\end{array}$ & & 1350 & 250 & 25 & 15 & $\begin{array}{l}53 \times 45 \\
\times 19\end{array}$ & $\begin{array}{l}43 / 4 \\
0\end{array}$ & 2 \\
\hline $\begin{array}{l}\mathrm{H}-\mathrm{K} 2 \\
03\end{array}$ & & 1500 & 300 & 25 & 15 & $\begin{array}{l}58 \times 28 \\
\times 35\end{array}$ & $\begin{array}{l}38 / 1 \\
6\end{array}$ & 1 \\
\hline
\end{tabular}

The suspension type miniature electric hoist belongs to the miniature electric hoist, and the suspension type miniature electric hoist can only be used in the trolley car.

Model: HXS.

Rated starting weight: $100 \mathrm{~kg}, 150 \mathrm{~kg}, 250 \mathrm{~kg}, 200 \mathrm{~kg}$.

Lift height: $20 \mathrm{~m}$. 
Rising speed: $15 \mathrm{~m} / \mathrm{min}(150 \mathrm{~kg}, 100 \mathrm{~kg}) 12 \mathrm{~m} / \mathrm{min}(200 \mathrm{~kg}, 250 \mathrm{~kg})$.

Gross / net weight: 28/27 30/29.

Rated voltage: 100/110/120/220/230/240.

The tension of the single hook is $200 \mathrm{~kg}$, which can meet the requirements. Therefore, H-K201 micro electric hoist is chosen. Seeing from Table H-K201, micro electric hoist height is 25 meters, lifting weights can be larger $200 \mathrm{~kg}$, the cut phase comparison is concemed and the price is relatively cheap, which is in line with the requirements.

Wire rope pulling force calculation. The minimum breaking of the wire rope is calculated according to the Ma core. The safety load is assumed by the design of steel truss or steel beam and the matching of the wire rope. If the wire rope end is used for other end connectors, the steel wire rope clip is recommended to reduce $25 \%$, and the loss of aluminum alloy is recommended to reduce $10 \%$.

Single pulley block $\mathrm{S}=\mathrm{Q} / \mathrm{a} \eta$, where is the block rate, $\eta$ stands for pulley efficiency.

The breaking strength of wire ropes is related to the wire breaking strength and the breaking tensile strength of wire ropes. Wire rope breaking force can be calculated by approximate formula: breaking force $=50 *$ diameter $*$ diameter. Wire rope safety factor: for cable wind: 3.5 . The diameter of wire rope obtained by calculation is 6 .

Axis calculation. Firstly, the intemal force of the circular shaft is analyzed, then the stress and deformation of the shaft are calculated, and the strength and rigidity of the shaft are calculated.

Calculation of the external force couple moments. 2.5.1

$$
M_{e}=9.55 \times 10^{6} \frac{P}{n}
$$

$\mathrm{M}$ e is $\mathrm{N}$ Torque $(\mathrm{N} \cdot \mathrm{mm})$. Power $\mathrm{P}$ is power $(\mathrm{W}) . \mathrm{n}$ is Rotational velocity $(\mathrm{r} / \mathrm{min})$. Steering couple mo ment is generated by the input power of the driving wheel and the shaft in the same direction; arising from the output power of the wheel moment of the couple of the steering shaft and in the opposite direction too. According to the design data, in the formula, $\mathrm{M} \mathrm{e}=9550 * 2.2 / 910=23 \mathrm{Nm}$.

The moment of inertia and the coefficient of torsion cross section is the geometrical properties of the cross section. The size of the cross section is related to the shape and size of the section. Solid axis shaft solid is D, then:

$$
\begin{aligned}
& I_{P}=\frac{\pi}{32} d^{4} \approx 0.1 d^{4} \\
& W_{P}=\frac{\pi}{16} d^{3} \approx 0.2 d^{3}
\end{aligned}
$$

For the stepped shaft, because the torsional section coefficient $\mathrm{Wp}$ is not constant, the maximu $\mathrm{m}$ working stress $t$ max does not necessarily occur in the section of the maximu mtorque $\mathrm{M} t$ max. To take into account the torque $\mathrm{T} \mathrm{M}$ and torsional section coefficient $\mathrm{Wp}$, according to these two factors, determine the maximu $m$ shear stress $t$ max.

Angle of Twist-the relative angular displacement of any two cross section when the shaft is twisted. Torsional angle $\mathrm{f}$ is a measure of torsion deformation.

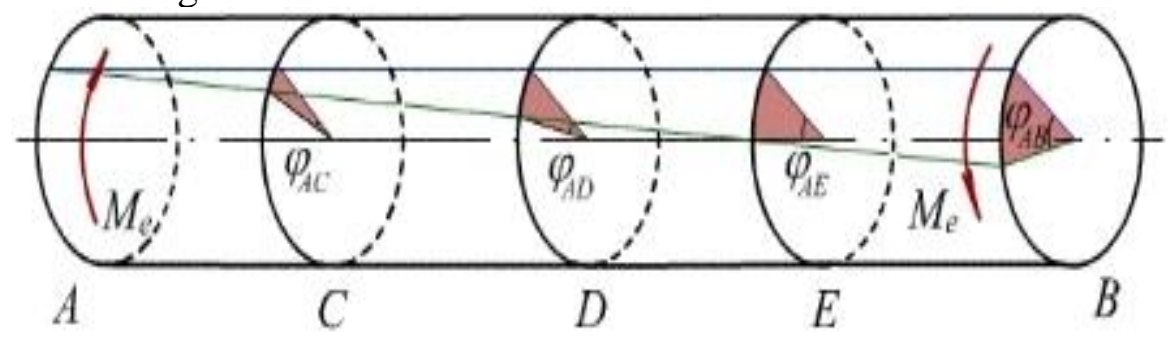

Two the distance of the cross section is the larger the angle of torsion is. 
Torque angle fof the straight round shaft is proportional to torque $\mathrm{M} \mathrm{T}$ and the length of shaft $\mathrm{L}$, and is inversely proportional to the polar inertia moment I P of the cross section, and the proportional constant $\mathrm{G}$ is introduced.

$$
\begin{gathered}
\phi=\frac{M_{T} L}{G I_{p}} \\
\Delta L=\frac{F_{N} L}{E A}
\end{gathered}
$$

$\mathrm{f}$ is the torsional angle and the shear modulus of $\mathrm{G}$ is the material. If the section between the torque value change, or shaft diameter difference should be segmented calculated corresponding sections of the torsion angle are then superimposed.

The rigidity condition of the straight round shaft: the maximu m unit length twist angle is less than or equal to the torsion angle of the leng th of the allowable unit.

\section{Use requirements}

If hoist is used as often as necessary, based on a base of the rack body placement on the concrete foundation, depth should not less than $1 \mathrm{~m}$. When it is used on the ground, rolling pile and rolling prison must be used and the base rolling pile should not be less than $8 \mathrm{~m}$. The angle of rolling pile is available for $75 \mathrm{~mm} \times 75 \mathrm{~mm}$. The driven und erground depth should be $1.2 \mathrm{~m}$. The rolling piles at the top of the frame body must be connected firmly with the chassis.Accord ing to the design requirements, the concrete foundation being buried the foot should be connected with bolt frame body.

\section{Conclusions}

By the computer aided design software of CAXA electronic drawing board, detailed calcu lation and description of each important and necessary step are checked. Assembly drawings and part drawings in accordance with the habit of the national mechanical drawing standards. Through this design, the author becomes more familiar with the relevant standards, norms, technical documents and design specifications of preparation. The analysis solves the question and the ability has been improved. The comprehensive use of the knowled ge can solve some practical problems in production.

\section{References}

[1] Weiguo Zhang . Mechanical design basis [M]. Wuhan: Huazhong University of Science and Technology, 2002.

[2] Kezhen Yang, Guangyun Cheng, Zhongsheng Li . Fundamentals of mechanical design (Fifth Edition). Beijing: Higher Education Press, 2007.5.

[3] Zhixin Zeng, Ming Lv . Basic [M]. Wuhan: Wuhan Tech Press, 2008.1.

[4] Ping Jiang, engineering mechanics basis [M]. Beijing: Education Press, 2004.5.

[5] Jiansheng Wu, engineering mechanics [M]. Beijing: Mechanical Industry Press, 2008.1.

[6] Daxian Cheng, mechanical design handbook. Beijing: Chemical Industry Press, 2004.1.

[7] Chunyuan Jiang, mechanical design manual. Shenyang: Liaoning Science and Technology Press, 1990.12.

[8] Liming Yang, design handbook for mechanical components. Beijing: National Defense Industry Press, 1989.12.

[9] J.E.Shigley:Mechanical Engineering Design,3rd Edition MeGraw-Hill,1977. 
[10] M.F.Spotts:Design of Mechanical Elements,5th Prentice-Hill,1978. 